\title{
The Impact of Non-Financial Incentives on Academic Staff Retention at Higher Education Institutions: An Exploratory Study in Oman
}

\author{
Amal Al-Qarshoubi \\ School of Education, University of Glasgow, UK
}

\begin{abstract}
Staff retention is an important issue for any organisation wishing to function well. This paper will focus on the drivers of academic staff retention at Omani higher education institutions, where this issue is still under-researched. Factors affecting academic staff retention can be classified to financial and non-financial incentives. However, the focus in this paper will be on non-financial incentives and the findings revealed from the qualitative approach. Non-probability sampling techniques were used to select the participants, and consequently face-to-face semi-structured interviews were conducted with 16 academic staff members. The selection criteria considered including academic staff with different demographic characteristics to ensure effective comparisons could be made between the different groups of the sample and to enrich the study with a broader range of perspectives. The findings revealed that several types of non-financial incentives, such as leadership and supervision skills, academic growth, autonomy, teaching resources, and recognition can influence the retention of academic staff.
\end{abstract}

Keywords: academic growth; autonomy; leadership; recognition; resources 